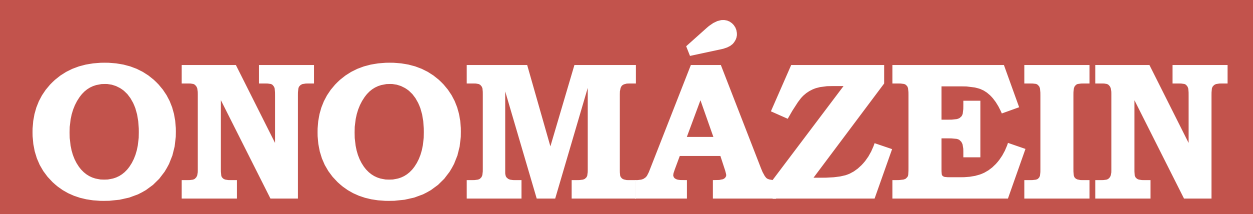

Revista de lingüística, filología y traducción
PONTIFICIA UNIVERSIDAD

\title{
Sobre el texto turístico promocional como unidad de significado: los componentes espacial, temporal y prospectivo
}

About the promotional touristic text as

a unit of meaning: the spatial, temporal

and prospective components

\author{
José María Castellano Martínez \\ Universidad de Córdoba
}

Número especial

- VII -

Discurso

turístico,

lenguas y

traducción

2020
ONOMÁZEIN | Número especial VII - Discurso turístico, lenguas y traducción: 127-144

DOI: 10.7764/onomazein.ne7.09

ISSN: 0718-5758

\section{(c) $($ i $)$}

José María Castellano Martínez: Universidad de Córdoba. ORCID: 0000-0002-8179-1590 | E-mail: I52camaj@uco.es 


\section{Resumen}

El presente trabajo de investigación propone analizar los denominados textos turísticos promocionales en cuanto unidades de significado que operan en el contexto discursivo turístico. A partir del concepto de significante mitológico propuesto por Febas (1978) en el marco de la teoría de la comunicación turística, y considerando los principios del funcionalismo traductológico, se aprecian tres componentes en este tipo de textos en lo que respecta a su justificación denominativa "turística” y "promocional”: el componente espacial, el componente temporal y el componente prospectivo. El desarrollo argumentativo y teórico de dichos componentes encuentra apoyo en el corpus textual trilingüe (español, francés, inglés) extraído del material promocional del Instituto de Turismo de España - TURESPAÑA.

Palabras clave: traductología; texto turístico promocional; significante mitológico.

\section{Abstract}

This paper aims to analyse the said promotional touristic texts as units of meaning that operate within the tourism discourse. Based on the concept of mythological signifier proposed by Febas (1978) in the framework of the touristic communication theory, and considering the principles of the translotological functionalism, three components can be distinguished in this type of texts concerning their "promotional" and "touristic" denominations: the spatial component, the temporal component and the prospective component. The theoretical and argumentative development of these components are accompanied by examples from a trilingual textual corpus (Spanish, French, English) extracted from the promotional material of the Instituto de Turismo de España - TURESPAÑA (the Spanish Tourism Institute).

Keywords: translatology; promotional touristic text; mythological signifier. 


\section{Introducción}

El turismo es uno de los sectores socioeconómicos más característicos de las sociedades contemporáneas. Desde su surgimiento, esta forma de consumo se caracteriza por haber desarrollado un contexto comunicativo que, sin llegar a la tecnificación propia de otros sectores más crípticos en sus terminologías o fraseologías, se compone de textos prototípicos (Reiss, 1976; Calvi, 2010, 2019) orientados a la promoción de un determinado destino para su posterior consumo a través de múltiples experiencias. En este sentido, Sulaiman y Wilson (2018: 633) resaltan la finalidad de consumo de este tipo de textos cuando afirman que el propósito del lenguaje promocional turístico es hacer que la gente consuma turismo, es decir, convertir en turistas a los lectores del texto. Esta pretendida metamorfosis por la que el lector del texto turístico promocional se convierte en turista precisa de reflexión en lo que se refiere al texto como unidad de significado traducible. En tanto que un texto original (en adelante "TO") ha sido diseñado en un determinado interés y pretende suscitar una respuesta, actitud o comportamiento en su lector a partir de una lengua original (en adelante "LO"), es necesario reflexionar en torno a los elementos, aspectos, factores o - denominémoslos así - componentes que configuran dicha unidad con especial énfasis en cómo se traslada a lenguas meta (en adelante "LM") en sus respectivos textos meta (en adelante "TM") o traducciones. La producción de textos orientados a la promoción turística no responde a un procedimiento uniforme, pues, como se ha advertido anteriormente, en el contexto comunicativo turístico se generan textos prototípicos que comparten fundamentalmente el propósito común de promocionar un destino; por lo tanto, se carece de teoría o "ciencia" turísticas que sustenten textología, terminología o fraseología propias. sin embargo, en tanto que la finalidad queda condicionada por el consumo de destinos (turísticos), el presente trabajo de investigación parte de los postulados enmarcados en la teoría comunicacional turística, especialmente en el concepto de significante mitológico de Febas (1978). En términos metodológicos, este trabajo parte de una fundamentación teórica sobre la que justificar la propuesta de componentes, para lo cual se han extraído ejemplos de un corpus (español, francés, inglés) integrado por los folletos y guías digitales sobre destinos turísticos ofrecidos por el Instituto de Turismo de España - TURESPAÑA en su sitio web oficial ${ }^{1}$.

1 Instituto de Turismo de España TURESPAÑA. Folletos y guías digitales. Disponible en <https://www. spain.info/es/folletos/destinos/\#ul_4>. El corpus se corresponde con el material promocional oficial de destinos turísticos de TURESPAÑA. La extensión del mismo ha hecho posible la operatividad del estudio en tiempo y forma. Los textos que integran el corpus de trabajo se corresponden con las guías turísticas en lengua española, inglesa y francesa de Barcelona, Bilbao, Costa Mediterránea, Córdoba, San Sebastián, España interior, España verde, Granada, Islas Baleares, Islas Canarias, Madrid, Málaga, Pueblos con encanto, Salamanca, Santiago de Compostela, Sevilla y Valencia. 
En definitiva, la presente propuesta pretende reflexionar en torno a un marco de análisis del texto turístico promocional entendido como unidad de significado que se condiciona por el contexto discursivo turístico en cuestión a diferencia de otros textos de carácter promocional o publicitario. En este sentido Pierini (2007: 99) advierte de la complejidad del discurso turístico promocional -impregnado de aspectos culturales y lingüísticos específicos-, por lo general subestimado por parte de clientes y traductores. En consonancia con la autora y con el propósito de contribuir a la definición del segmento turístico en los estudios de traducción, se presumen tres componentes (espacial, temporal y prospectivo), a tenor de lo cual se perfila el objetivo de este trabajo de investigación: proponer un marco analítico aplicable a los textos turísticos promocionales (TO/TM) que justifique así la denominación "turística promocional”.

\section{El texto turístico promocional como unidad de significado}

La denominación de texto turístico promocional, frente al simple texto turístico, se prefiere en este trabajo por cuanto se limita a los textos de finalidad promocional de destinos (guías, folletos, trípticos, etc.), frente a otros posibles textos que también pudieran darse en el contexto discursivo turístico (billetería, seguros de viajes, menús, protocolos, señaléticas, etc.). Se trata de un texto operativo cuyo nivel de sugestión resulta variable, pues pretende suscitar una reacción en el destinatario para influir en su opinión e inducir a acciones concretas (Reiss, 1976: 35), como, por ejemplo, el deseo o la curiosidad por conocer un determinado lugar. Tal capacidad de influencia guarda relación con el denominado "significante mitológico" presumido por Febas (1978: 122), quien reconoce de forma implícita la consideración de unidad de significado al afirmar que el texto turístico (promocional) es "un universo cerrado, dotado de un sentido global y autónomo, que se convierte en significante de un nuevo sistema, el de la comunicación turística”. Con esto, el autor viene a confirmar la abstracción, y, por tanto, interpretación basada en sugestión, que el acceso al texto genera en el lector en tanto que esta unidad de significado se somete a las normas de un contexto comunicativo propio, el del turismo. Si bien desde la sociolingüística turística destaca la archiconocida obra de Dann (1996), es cierto que en esta se hacen múltiples referencias a Febas, pudiéndose considerar sin duda uno de los precursores de la teoría de la comunicación turística.

En su propuesta de triangulación temática, Febas analiza el texto turístico promocional desde una perspectiva semiológica en donde la relación verbal y visual adquiere especial relevancia en cuanto a la organización de las secuencias temáticas del texto. La triangulación deconstruye el texto turístico en torno a campos isotópicos — como la gastronomía, el patrimonio o los servicios turísticos - que coinciden a su vez con los vértices de los cuatro triángulos que el autor propone (imagen 1). De este modo, es posible aproximarse al conjunto de secuencias en las que más profundiza el texto en cuestión. 


\section{IMAGEN 1}

La triangulación temática de Febas (1978: 32)

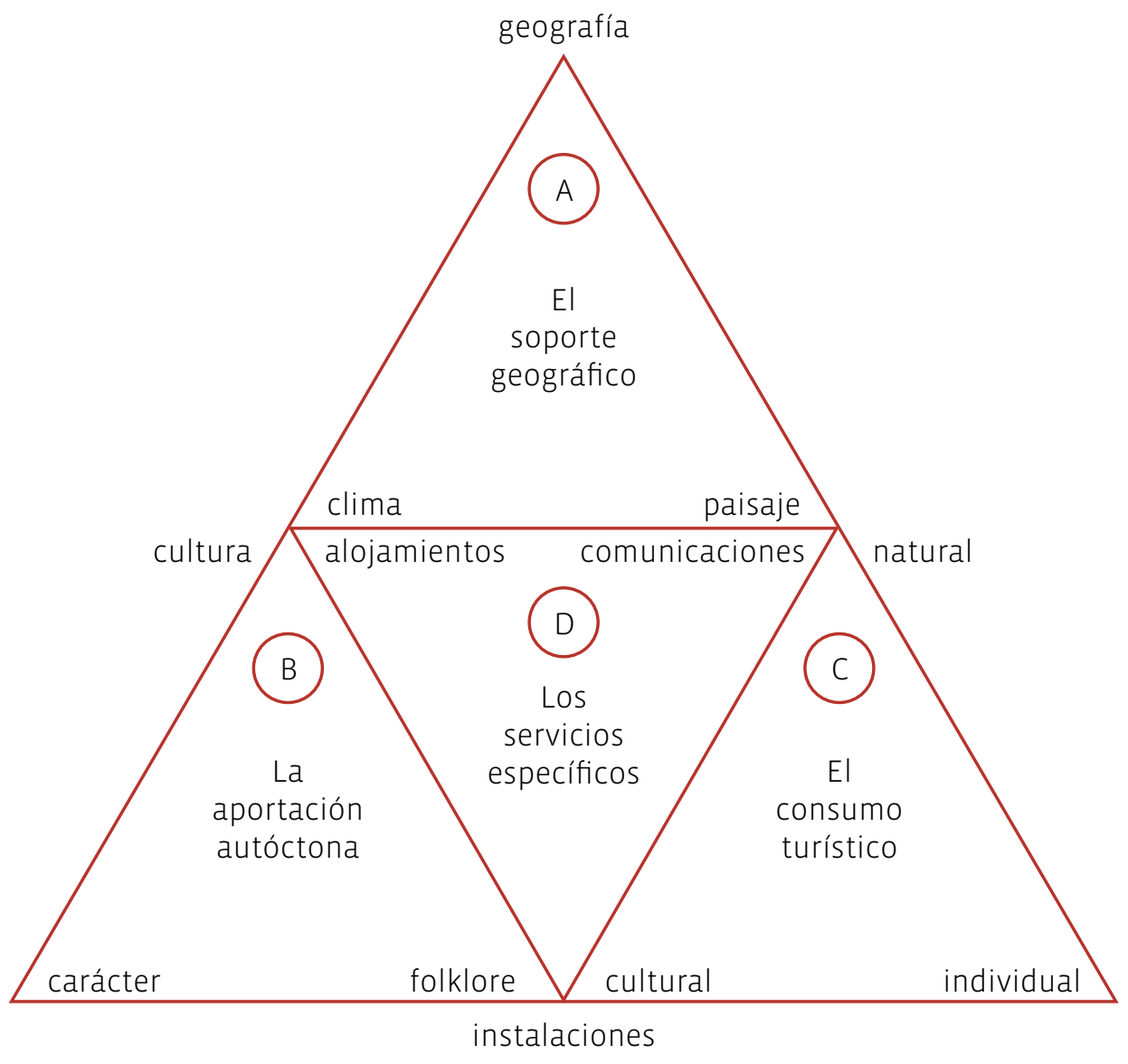

Una de las principales características por las que el texto turístico promocional predispone la sugestión del lector es el hecho de que precise de imagen además de elemento verbal. Entre ambos elementos surge un valor, se podría decir, próximo a la iconotextualidad (Heffernan, 1993; Wagner, 1996; Pimentel, 2003), no tanto por su relación con los campos de la crítica literaria o de la retórica de la imagen cuanto por el hecho de que participe en la conceptualización del mencionado significante mitológico. La orientación al consumo del texto hace que el lector participe de él. No se trata de una écfrasis en sentido estricto, pues el elemento verbal no tiene que describir el visual; más bien es una simbiosis en la que el elemento visual y verbal se complementan. Esto encajaría en el enfoque paratraductivo desarrollado por la Escuela de Vigo, a partir de la teoría del "paratexto" literario de Genette. En palabras de Yuste (2015: 322): "El estudio pormenorizado de las entidades iconotextuales, el mínimo análisis de las producciones verbales, icónicas, verbo-icónicas y materiales que rodean, envuelven, acompañan, introducen, presentan y prolongan el texto de un encargo de traducción impusieron la creación de la nueva noción de paratraducción”. 


\section{Propuesta de componentes del texto turístico promocional}

La formulación de este tipo de texto se desarrolla en torno a un destino turístico que es objeto de promoción. La traducción implica una inmediata traslación de dicho objeto a otras lenguas, y, por ende, a otros "espacios" socioculturales. Esta descontextualización del entorno concebido en LO hacia otro virtual en LM es un constructo en el que participan los componentes aquí propuestos. En consonancia con el enfoque traductológico funcionalista, destaca el valor icónico del texto turístico promocional en cuanto que el acceso al documento implica una metaoperación interpretativa en la que los destinatarios recrean o imaginan los valores atribuidos al significante mitológico del texto. Por ello, la traducción de este tipo de textos no se ciñe exclusivamente a terminologías o fraseologías derivadas de un campo del saber concreto, sino que precisa desglosar los componentes que lo integran como unidad de significado, más allá del plano lingüístico (Certeau, 1984: 116).

Certeau (ibid.) esboza que la traducción deberá, además de reformular o representar en el TM el TO, evocar dicho destino e incitar a su consumo. En esta línea, Cronin (2000) señala que la mayoría de los turistas - en cuanto consumidores - precisan de la visualización del destino todavía desconocido (aunque imaginado), pues en ocasiones desconocen la lengua del objeto al que desean dirigirse, acceder o "consumir". Esta reflexión es interesante ya que confiere importancia a la LM, pues la reformulación del texto en otra lengua aproxima el exotismo del objeto turístico al receptor/consumidor, o sea, el turista, quien accede al significante mitológico del texto.

El texto turístico promocional forma parte de un discurso. Son las actividades turísticas las que determinan un contexto y, por ende, un discurso en donde el texto promocional, a diferencia del meramente publicitario, incita a la acción, al movimiento, al consumo de un destino. Este invite a la experiencia turística se sustenta en el mencionado significante mitológico propuesto por Febas, incluso en la referencia a la reactivación del locus amoenus de Bugnot (2009). Para analizar el constructo textual por el que se incita a la experiencia turística a través del consumo del destino, se proponen los siguientes componentes como elementos definitorios del texto turístico promocional.

\subsection{El componente espacial}

El territorio representa el aspecto espacial y físico en el que se encuentra el objeto turístico que se promociona. Se trata del soporte geográfico y determina un contexto real integrado por aspectos variopintos y de características propias. El primer triángulo propuesto por Febas (1978: 36) se correspondería con este componente, al que el autor dota de un valor referencial relacionado con la geografía, el clima y el paisaje.

El componente espacial forma parte del objeto en sí y genera "paisajes" " "miradas" al respecto por parte del lector. De hecho, este espacio no debe contemplarse de forma estática, sino 
dinámica, pues el circuito textual en el que se integra lo dota de personalidad. Se trata de la disyuntiva ya formulada por Milton (1993) entre land y landscape con respecto a la construcción del entorno: frente al estatismo que el mero concepto geográfico de territorio representa, se formula un "paisaje" dinámico (idealizado, construido, visualizado) con un determinado propósito promocional. El territorio se convierte en objeto de consumo para el turista, tal y como Urry (2005: 21) advierte en su conceptualización del "consumo del lugar", el cual se torna en "paisaje" porque se describe y dota de contenido, se contempla (tourist gaze) (op. cit., 25-26) y consume a través del texto que lo promociona (TO, TM).

La "mirada" (gaze)² se dirige hacia el objeto turístico en cuanto conjunto de signos y referencias de un espacio escénico que se define como destino (Urry, 1995: 133). Este escenario es un artificio fruto de un proceso de asimilación cultural en constante reinterpretación. Así Io afirma Green (1990: 3) cuando se refiere al paisaje como una sensación que se percibe, un scenario; o Zukin (1991: 7) al reconocer que el paisaje material es resultado de un proceso de apropiación cultural en el que la historia de su creación queda vinculada al consumo visual del mismo. La formulación de este componente determinará el universo narrativo del texto, se asemeja a un escenario en el que se precisará o prescindirá del atrezo de la obra/relato que sobre él se desarrolla: no se promociona el territorio, sino el espacio en el que se concibe el destino turístico. En el corpus se aprecian dos tipos de componentes espaciales: destinos concretos (64,7\%) frente a aquellos que presentan mayor grado de abstracción (35,3\%) en su definición territorial al incorporar varios espacios bajo una denominación de conjunto geográfico o interés promocional (véase la tabla 1 en la página siguiente).

\subsection{El componente temporal}

El texto turístico promocional precisa del verbo, es decir, de un tiempo en el que se desarrolla el anterior espacio. De ahí que en el componente temporal se recurra a fórmulas y estrategias, predominantemente verbales, aunque también visuales (Dann, 1996: 171), con las que desarrollar un relato sugerente, atractivo y que, en definitiva, seduzca al potencial turista con el fin de que interprete el significante y lo interiorice. Para conseguir suscitar dicho pathos (Ammossy, 2000; Bugnot, 2009), en cuanto emoción o deseo hacia el objeto turístico, el relato se justificará sobre técnicas argumentativas relacionadas con el componente espacial.

Este tiempo recrea una hiperrepresentación del objeto turístico a través de recursos narrativos, simbólicos o iconográficos de fuerte carga apelativa y poética. De ello se deriva también la dicotomía entre lo auténtico e irreal, lo natural y lo turístico, que Culler define como "a

2 En su obra, Urry diferencia varios tipos de miradas (gazes) según el perfil del turista en cuestión, hecho que podría vincularse al componente expectativo: romantic gaze, collective gaze, spectatorial gaze, reverential gaze, anthropological gaze, environmental gaze y mediatised gaze. 


\section{TABLA 1}

Componentes espaciales concretos y abstractos extraídos del corpus

\begin{tabular}{cc}
$\begin{array}{c}\text { COMPONENTES ESPACIALES } \\
\text { CONCRETOS }\end{array}$ & $\begin{array}{c}\text { COMPONENTES ESPACIALES } \\
\text { ABSTRACTOS } \\
\text { Barcelona }\end{array}$ \\
\hline Bilbao & Esta mediterránea \\
\hline Córdoba & España verde \\
\hline Granada & Islas Canarias \\
\hline Madrid & Islas Baleares \\
\hline Salamanca & Pueblos con encanto
\end{tabular}

San Sebastián

Santiago de Compostela

Sevilla

Valencia

powerful semiotic operator within tourism" (1981: 131). Los siguientes extractos pretenden esbozar el momento o tiempo que el texto construye para la expectativa de experiencia turística del lector:

\section{TABLA 2}

Extractos textuales de carga apelativa o poética a partir del corpus

\begin{tabular}{|c|c|c|}
\hline $\begin{array}{l}\text { “(...) Déjate seducir por } \\
\text { su color, sus aromas y su } \\
\text { ambiente y atrévete a } \\
\text { conocer sus leyendas y } \\
\text { misterios más fascinantes. } \\
\text { (...) Compruébalo en mayo, } \\
\text { cuando sus calles se } \\
\text { perfuman con el aroma del } \\
\text { jazmín, (...). [Córdoba, p. 3] }\end{array}$ & $\begin{array}{l}\text { “Paseando descubrirás } \\
\text { una ciudad milenaria con } \\
\text { un patrimonio histórico } \\
\text { único. (...) con estrechas } \\
\text { calles escoltadas por } \\
\text { impresionantes edificios } \\
\text { de granito. Por momentos, } \\
\text { no sabrás si te encuentras } \\
\text { en el presente, en el } \\
\text { Renacimiento o en pleno } \\
\text { Siglo de Oro español”. } \\
\text { [Santiago de } \\
\text { Compostela, p. 4] }\end{array}$ & $\begin{array}{l}\text { "Descubre encantadoras } \\
\text { poblaciones de calles } \\
\text { empedradas, castillos } \\
\text { y fortalezas en las } \\
\text { que el tiempo parece } \\
\text { haberse detenido". } \\
\text { [Pueblos con encanto, p. 12] }\end{array}$ \\
\hline
\end{tabular}

Estas hiperrepresentaciones se conciben a propósito, en ellas se idea e idealiza el objeto en un contexto comunicativo orientado al consumo. En este sentido, Edensor (2002: 13) destaca la narración, junto con la simbología, las imágenes y otras fórmulas, como uno de los princi- 
pales instrumentos generadores de ideas para propiciar el consumo en el marco de la mercadotecnia turística. En lo que concierne a la traducción de dicha narración destaca el concepto de transcreación en cuanto que la presencia de código verbal y visual condicionará la estrategia de adaptación o reformulación del TO en LM (Ray y Kelly, 2010). Desde un punto de vista crítico, la transcreación -intrínsecamente relacionada con la publicidad y el marketing-, al igual que la adaptación, la mediación o la localización en sus respectivos contextos, puede cuestionar el propio concepto de traducción de tal modo que "se perciba como un término insuficiente, incluso devaluado frente a otras posibilidades abiertas especialmente por la traducción profesional” (Fernández, 2019: 227, citando a Gambier, 2016: 888). No obstante, dicha capacidad creativa se precisa para la traducción de los objetos culturales específicos —realia (Florin, 1993), culturemas (Nord, 1997; Katan, 2009), etc.- presentes en el componente temporal. La ubicación sociocultural de este tipo de conceptos no tiene por qué existir en $L M, y$, por lo tanto, no siempre es posible el trasvase de las funciones y connotaciones vinculadas a los mismos. De hecho, para González-Pastor (2017: 39) "existe una intraducibilidad cultural intrínseca al acto traductológico mismo (...)". Asimismo, la finalidad promocional del texto condiciona la formulación del TM, cuyo riesgo inventivo y creativo puede verse condicionado por la interferencia extrema de la LM y los réditos y beneficios que esto puede generar en el TM (Pym, 2008: 325) en aras de la aceptación receptora. Los siguientes extractos recogen algunos de los culturemas presentes en el corpus3:

\section{TABLA 3}

Selección de culturemas originales y traducidos

\begin{tabular}{|c|c|c|}
\hline VERSIÓN EN ESPAÑOL & VERSIÓN EN FRANCÉS & VERSIÓN EN INGLÉS \\
\hline $\begin{array}{l}\text { Vayas donde vayas te } \\
\text { ofrecerán el sencillo pero } \\
\text { delicioso pa amb tomàquet } \\
\text { tomate frotado sobre pan } \\
\text { tostado, con sal y aceite de } \\
\text { oliva. [Barcelona, p. 10] }\end{array}$ & $\begin{array}{l}\text { Où que vous alliez, le «pa } \\
\text { amb tomàquet » est une } \\
\text { institution simple mais } \\
\text { délicieuse : une tartine de pain } \\
\text { grillé frottée avec une tomate } \\
\text { bien mûre et assaisonnée } \\
\text { de sel et d'huile d'olive. }\end{array}$ & $\begin{array}{l}\text { Wherever you go you will } \\
\text { be offered the simple but } \\
\text { delicious pa amb tomáquet } \\
\text { tomato rubbed on toasted } \\
\text { bread, with salt and olive oil. }\end{array}$ \\
\hline $\begin{array}{c}\text { La marcha nocturna se } \\
\text { concentra en cuatro zonas, } \\
\text { en las que los cordobeses se } \\
\text { dan cita para vivir la noche en } \\
\text { buena compañía, entre tapas, } \\
\text { copas y diferentes ritmos } \\
\text { musicales. [Córdoba, p. 22] }\end{array}$ & $\begin{array}{l}\text { La fête nocturne se concentre } \\
\text { dans quatre zones, où } \\
\text { les habitants se donnent } \\
\text { rendez-vous pour vivre la } \\
\text { nuit en bonne compagnie, } \\
\text { entre verres et tapas, au } \\
\text { son de rythmes variés. }\end{array}$ & $\begin{array}{l}\text { The nightlife is concentrated } \\
\text { in four areas, where the } \\
\text { people of Cordoba meet } \\
\text { to spend the night in } \\
\text { good company, enjoying } \\
\text { tapas, drinks and different } \\
\text { styles of music. }\end{array}$ \\
\hline
\end{tabular}

3 El texto entrecomillado, en cursiva o negrita se corresponde con la forma original de los textos del corpus. Se subrayan los culturemas y sus traducciones. 
La noche del Miércoles Santo tiene lugar el paso del Cristo de los Gitanos, espectacular y emocionante gracias a las inmensas fogatas que se prenden en las calles del Sacromonte. [Granada, p. 15]

Si hay una fiesta popular en la isla de La Palma es la danza de los enanos. [Islas Canarias, p. 21]
Le soir du Mercredi saint, la procession du Cristo de los Gitanos offre un spectacle magistral et émouvant grâce aux immenses feux de joie allumés dans les rues du quartier du Sacromonte.

S'il y a une fête populaire sur l'île de La Palma, c'est la danse des nains
On the night of Ash

Wednesday you have the

Paso de los Gitanos, a spectacular, moving event with huge bonfires in the streets of the Sacromonte.

The most popular festival on the island of La

Palma is the so-called

dance of the dwarfs.

No obstante, en lo que respecta al uso (y abuso) de este tipo de conceptos, Calvi (2019: 83) advierte de la importancia que tiene la selección de información cultural contenida tanto en la formulación del TO como en la reformulación en LM (véase el ejemplo de "paso"). Esto determinará el nivel de accesibilidad y, por ende, la comprensión del lector, así como la inteligibilidad del TO y del TM4 4 . Llegados a este punto, resulta pertinente retomar la aplicabilidad de la epistemología paratraductiva con respecto del mercado profesional, pues, según Yuste (2015: 332), es el traductor y exclusivamente él quien debe formular el TM en relación con la orientación que estime pertinente conferirle, sin que agentes ajenos al mismo (editores, instituciones, impresores, etc.) puedan interferir en cualquier aspecto textual que afectase a la finalidad y comprensión del TM. La traducción del texto turístico promocional queda condicionada por este componente en el que las funciones apelativa y poética del lenguaje modulan la operatividad conferida por Reiss. Concretamente, la reformulación de dichas funciones -y connotaciones - en LM precisa por parte del traductor de la búsqueda de un equilibrio entre el TO y el TM en torno a la accesibilidad, asequibilidad y operatividad de la traducción según las situaciones específicas del encargo (Agorni, 2016: 18), en el que surgirán problemas y dificultades (Durán, 2012), además de retos — como los relacionados con la cuestión cultural-(Valdés, 2013: 311). La tabla 4 esboza algunos ejemplos5.

En el marco del corpus de trabajo, y tal y como reflejan los ejemplos seleccionados, se aprecia un enfoque funcionalista que preserva las funciones informativa y apelativa del TO con respecto de sendos TM por encima de cuestiones formales.

4 En relación con dicha accesibilidad, Calvi (op. cit.) propone tres modalidades de traducción (intralingüística, de mediación intercultural e interlingüística) en función de las necesidades y expectativas del turista. Apréciense las soluciones aportadas en las respectivas traducciones.

5 Los extractos seleccionados pretenden ofrecer una muestra de resoluciones traductoras. Se subraya el elemento de interés, así como se indica entre corchetes la técnica o variación que se aprecia. El resaltado en negrita es original. 
TABLA 4

Selección de extractos comparados

VERSIÓN EN ESPAÑOL

Ríndete a los encantos de Bilbao y todos tus sentidos se verán recompensados. [Bilbao, p. 3]

Prepárate para disfrutar de su deliciosa gastronomía en las tabernas de pequeños pueblos marineros, en sus restaurantes con estrella Michelin o en sus bodegas de diseño. Después, prepárate para una tarde de compras o para un inolvidable atardecer frente al mar. [España verde, p. 3]

Para reponer fuerzas después de tanta visita, prueba los famosos asados de lechazo y ternasco castellanos. Riégalos con los vinos de la zona y tendrás un menú delicioso. [España interior, p. 7]

\section{VERSIÓN EN FRANCÉS}

Succombez au

charme de Bilbao

et régalez tous vos sens. [modulación]

\section{VERSIÓN EN INGLÉS}

The charms of Bilbao are a delight for all the senses. [generalización, modulación]

You'll just love the delicious

Préparez-vous à savourer sa délicieuse gastronomie dans les tavernes de petits villages de pêcheurs, dans ses restaurants étoilés au guide Michelin ou dans ses caves œuvres d'architectes renommés. Puis préparez-vous pour une après midi (sic.) de shopping ou un coucher de soleil inoubliable face à la mer. [modulación]

Et pour reprendre des forces après tant de visites, succombez aux célèbres cochons et agneaux de lait grillés, les spécialités locales. À accompagner impérativement des crus de la région pour un menu tout à fait savoureux. [equivalente]

\section{Contempla el amplio abanico} de paisajes del parque natural de Ses Salines, que se extiende desde el sur de Ibiza al norte de Formentera, incluyendo el brazo de mar que separa las dos islas. [Islas Baleares, p. 23]
Contemplez la vaste gamme de paysages du parc naturel de Ses Salines, qui s'étend du sud d'Ibiza au nord de Formentera, incluant le bras de mer qui sépare les deux îles. [transcreación/adaptación] cuisine served in taverns in small fishing villages, Michelin-star restaurants or designer wine-cellars. Then prepare yourself for an evening's shopping and an unforgettable sunset by the sea. [modulación, reducción]

\section{After a very active day you deserve to reward yourself with some relaxation and a typical Castilian roast lamb meal together with a wine from the region. What a treat! [adaptación]}

\author{
You can look out over a \\ myriad of landscapes in \\ the Ses Salines Nature \\ Reserve which goes from \\ the south of Ibiza to the \\ north of Formentera and \\ includes the strait which \\ separates the two islands. \\ [transcreación/adaptación]
}

\subsection{El componente prospectivo}

El sujeto al que se dirige el texto turístico promocional es un receptor definido por su perfil consumidor en relación con una situación específica o un "conocimiento" o pretensión sobre el destino en cuestión. Riley denomina "comunidades epistémicas" (2002) a aquellos grupos sociales que se fundamentan en un determinado conocimiento especializado que deriva precisamente de aspectos identitarios y, por ende, discursivos. Este sistema de conocimiento social (Social Knowledge System, en adelante SKS) predispone al lector y gradúa su permeabi- 
lidad con respecto a la función apelativa del texto. Cuando el lector accede al texto, se transforma en potencial turista y comienza el ciclo de consumo del otro / experiencia turística. En el marco de dicha otredad, se formulan binomios múltiples (Dann, 1996: 4-33) en torno a los cuales surge la expectativa del lector desde diferentes perspectivas: familiar frente a exótico, cercano frente a lejano, oriundo frente a turista, conocido frente a desconocido, etc. He aquí la metarrepresentación del significante. Este depende de las motivaciones, expectativas y experiencias que cada consumidor albergue con respecto del objeto turístico en cuestión y de su correspondiente SKS. En nuestro interés traductológico, merecen especial mención las consideraciones que Fuentes (2005: 60) aporta sobre esta cuestión:

La traducción se muestra aquí como algo que con demasiada frecuencia queda limitado a lo lingüístico (o lo que es peor, a una mera equivalencia palabra por palabra, o imagen por imagen), pasando por alto factores clave como el grado de conocimiento que los potenciales lectores tienen acerca de la cultura origen, las expectativas de los lectores en cuanto a formato, presentación y contenido del texto publicitario, y la falta de información sobre las reacciones de los destinatarios, con las que reevaluar los textos y/o la marca-imagen traducidos.

A partir del significante mitológico, el lector genera imágenes y referentes, imagina momentos y situaciones, comienza su experiencia turística a partir de una metarrepresentación pretendida por el componente prospectivo del texto. De este modo, el turista participa en el discurso turístico proyectándose en su expectativa particular de la experiencia:

(...) the future-oriented work of preparing memories and of responding to the claims made by a place, and by people and materials encountered. Such emotional labour in the present to secure future narrative for memories indexes something of a paradox. The taking of photographs and the buying of souvenirs give material, sustainable form to what is ephemeral. It is a way of symbolically distilling present-tense experience into fragments and forms that have a durability beyond tourist time. It makes our tourists 'collectors' and orients them towards future times of memory (Jack y Phipps, 2005: 144).

Esta metarrepresentación condiciona la mirada que el sujeto dirige al objeto, así como su percepción; de ahí que la industria turística construya un significante en consonancia con las expectativas y deseos del consumidor (Bugnot, 2009: 104). El componente prospectivo se fundamenta en la adquisición —en sentido figurado- que el turista hace del objeto turístico,

6 “(...) el trabajo orientado al futuro en la preparación de recuerdos y respuestas a las pretensiones de un lugar, de personas y materiales que se encuentran. Tal labor emocional en el presente asegura la narrativa futura para poder recordar, lo cual tiene algo de paradoja. Hacer fotografías y comprar suvenires ofrece algo material, un sustento de aquello que es efímero. Es una manera de destilar en lo simbólico la experiencia del tiempo presente en fragmentos y formas que tienen mayor duración que el tiempo turístico en sí. Esto convierte a nuestros turistas en 'coleccionistas' y los dirige hacia momentos futuros que recordar". 
es decir, cuando el lector ve posible saciar sus necesidades e inquietudes (Uzzell, 1984: 80) a partir de la hiperrepresentación a la que accede, siendo esto un acto particular, imaginativo y de expectación. Las metarrepresentaciones derivadas de una misma hiperrepresentación se presumen por lo tanto infinitas y quedan condicionadas por el contexto social y cultural del lector. De hecho, la interacción de este con el destino hiperrepresentado a través del texto dota al significante mitológico de una mayor plurisignificación:

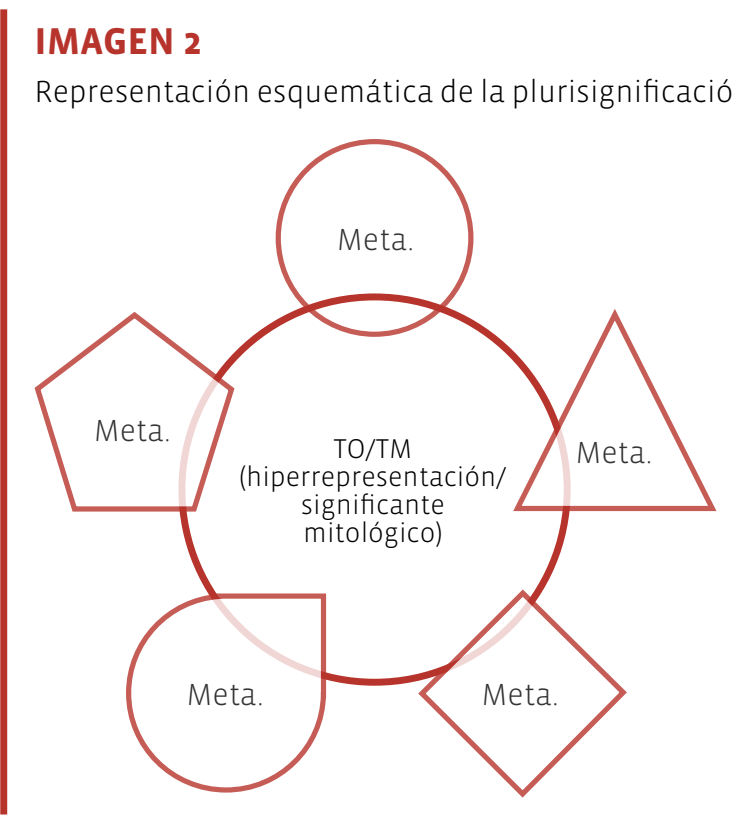

En cuanto que el componente prospectivo se fundamenta en la experiencia interpretativa de cada lector (hiperrepresentación > metarrepresentaciones), se podría considerar la calidad de la redacción y de la formulación del texto como un primer estadio desde el que valorar la prospección del documento (TO/TM). La formulación (TO) y reformulación (TM) del significante se fundamentan en la función informativa del texto, matizada por las funciones apelativa y poética como parte de la ficción que promueve dicho significante. Por ello, en su estudio sobre la calidad de folletos turísticos traducidos, Nobs (2006: 127) constata que "los sujetos penalizan más una falta de respeto de los elementos que remiten al contenido que una falta referida a elementos formales", esto es, que en términos relativos los "sujetos" o "usuarios reales", tal y como los denomina la autora, apremian el acceso y comprensión con respecto de la misma información contenida entre folletos turísticos frente a otras cuestiones (véase la tabla 4).

Por tanto, el componente prospectivo del texto turístico promocional incide, por una parte, en la consideración de las expectativas de los posibles turistas que el emisor formula (TO) o reformula (encargo del TM); por otra, en la experiencia turística del lector a partir de la recepción del texto (TO o TM), al cual se puede acceder en términos de evaluación y de calidad de los TO/TM. 


\section{Conclusiones}

La traducción de textos turísticos promocionales implica la reproducción de un espacio idealizado, de una visión reducida a una hiperrepresentación iconotextual, pero abierta al mismo tiempo a múltiples metarrepresentaciones sin más limitación que el significante mitológico del destino en sí.

Los tres componentes - espacial, temporal y prospectivo - se inscriben en los postulados de la teoría comunicativa turística y proponen una conceptualización del texto turístico promocional como unidad de significado compuesto de valores verbales e icónicos. Desde un enfoque traductológico funcionalista, dicha unidad de significado se concibe como texto operativo orientado al consumo, motivo por el que la estrategia de traducción y las técnicas aplicadas en la misma para la resolución de dificultades, problemas y retos entre TO y TM quedarán condicionadas por la operatividad iconotextual del significante mitológico.

Los componentes desglosados justifican el carácter "turístico promocional" del texto en el que se den, a diferencia de otros textos operativos como los publicitarios, que carecen de significante mitológico en el sentido de Febas. Por lo tanto, para que el texto turístico promocional sea denominado como tal, se precisará de un territorio que se convierta en destino por medio de una narración que suscite en el receptor una expectativa:

\section{IMAGEN 3}

Esquema de los componentes del texto turístico promocional

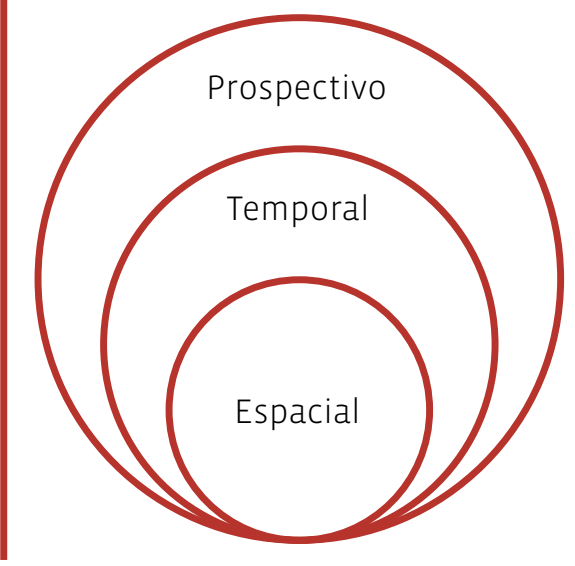

Se podría afirmar que el componente espacial es el principal elemento diferenciador de los textos turísticos promocionales con respecto al resto de textos publicitarios. Si bien el marco y la finalidad comunicativa son similares en los textos operativos orientados al consumo, los textos turísticos promocionales se fundamentan sobre un territorio que condiciona el texto en el plano narrativo. El componente espacial en sí representa un icono sobre el que narrar (temporal) y proyectar (prospectivo). Es el único elemento físico, en cuanto que real, con res- 
pecto del temporal que, si bien se materializa en el texto de forma palpable, se reduce a una hiperrepresentación del destino. No obstante, el componente temporal es de mayor interés lingüístico en cuanto que se integra de elementos verbales (traducibles), aunque estos se encuentren en simbiosis con elementos visuales. La presencia de estos elementos condiciona la disposición e interpretación textuales, lo cual afectará a la formulación del TM. Por su parte, el componente prospectivo puede ser objeto de interés para la formulación del TO o la reformulación en LM conforme con la orientación, el destinatario o el propósito que se desee conferir al mismo. De interés en lo que respecta al encargo de traducción es el componente que permite evaluar el texto en su conjunto a partir de la plurisignificación del significante y sus respectivas metarrepresentaciones. Por lo tanto, el componente prospectivo se sirve de las funciones lingüísticas y visuales del componente temporal, que a su vez parte de la hiperrepresentación del componente espacial.

En cuanto que la extensión del presente trabajo queda condicionada por cuestiones editoriales, en lo concerniente a ejemplos traductológicos apenas se ha esbozado una selección de las cuestiones tratadas. Esto posibilita continuar la investigación futura centrando el interés en cuestiones contrastivas del componente temporal de los textos del corpus (en el que se aprecia una mayor función poética en las versiones española y francesa con respecto de las inglesas), así como el estudio de la evaluación y calidad de las traducciones con respecto del componente prospectivo de los textos o la selección o configuración de destinos turísticos comprendidos como componentes espaciales.

La consideración de estos componentes que aquí se esbozan pretende establecer un punto de partida sobre el que profundizar en la conceptualización del texto turístico promocional en el marco de la teoría comunicativa turística, que, si bien ha estado condicionada por el enfoque sociolingüístico de Dann, no puede obviar la aportación pionera de la triangulación de Febas en la que se inspira esta propuesta.

\section{Bibliografía citada}

AgoRnI, Mirella, 2016: "Tourism Across Languages and Cultures: Accessibility Through Translation”, CULTUS 9 (2), 13-27.

Ammossy, Ruth, 2000: L’argumentation dans le discours, París: Nathan.

Bugnot, Marie-Ange, 2009: Le discours touristique ou la réactivation du locus amoenus, Granada: Comares.

Calvi, Maria Vittoria, 2010: "Los géneros discursivos en la lengua del turismo: una propuesta de clasificación", Ibérica: Revista de la Asociación Europea de Lenguas para Fines Específicos (AELFE) 19, 9-32. 
Calvi, Maria Vittoria, 2019: "Géneros discursivos, diversidad cultural y traducción de textos turísticos”, Altre Modernità: Rivista di studi letterari e culturali 21, 69-86.

Certeau, Michel de, 1984: The Practice of Everyday Life, Berkeley: University of California Press. Cronin, Michael, 2000: Across the Lines: Travel, Language and Translation, Cork: Cork University Press.

Culler, Jonathan, 1981: "Semiotics of Tourism", American Journal of Semiotics 1, 127- 140.

Dann, Graham M. S., 1996: The Language of Tourism. A sociolinguistic Perspective, Wallingford: CAB International.

Durán Muñoz, Isabel, 2012: "Caracterización de la traducción turística: problemas, dificultades y posibles soluciones”, Revista de Lingüística y Lenguas Aplicadas 7, 103-113 [https://doi. org/10.4995/rlyla.2012.1127].

Edensor, Tim, 2002: National Identity, Popular Culture and Everyday Life, Oxford y New York: Berg.

FEBAS, José Luís, 1978: "Semiología del lenguaje turístico (Investigación sobre folletos españoles de turismo)", Estudios Turísticos 57-58, 17-204.

Fernández Rodríguez, M. ${ }^{a}$ Amelia, 2019: “Transcreación: Retórica cultural y traducción publicitaria”, Castilla. Estudios de Literatura 10, 223-250 [https://doi.org/10.24197/cel.10.2019.223-250].

Florin, Sider, 1993: "Realia in translation" en Palma Zlateva (ed.): Translation as Social Action. Russian and Bulgarian Perspectives, Londres: Routledge, 122-128.

Fuentes Luque, Adrián, 2005: "La traducción de promoción turística institucional: la proyección de la imagen de España” en Adrián Fuentes Luque (ed.): La traducción en el sector turístico, Granada: Atrio, 59-92.

Gambier, Yves, 2016: "Rapid and radical changes in translation and translation studies", International Journal of Communication 10, 887-896.

GonzÁlez-PAStor, Diana María, 2017: "Sobre las estrategias de traducción de referencias culturales en el ámbito de la arquitectura (español-inglés)”, Entreculturas 9, 37-52.

GreEn, Nicholas, 1990: The Spectacle of Nature, Manchester: Manchester University Press.

Heffernan, James A. W, 1993: Museum of Words. The Poetics of Ekphrasis from Homer to Ashbery, Chicago, Londres: The University of Chicago Press. 
Jack, Gavin, y Alison PHIPSs, 2005: Tourism and intercultural exchange: why tourism matters, Channel View Publications, ProQuest Ebook Central [https://mezquita.uco.es/permalink/34CBUA_ UCO/1818mlf/almag91006144152504992].

Katan, David, 2009: "Translation as Intercultural Communication" en Jeremy Munday (ed.): The Routledge Companion to Translation Studies, Oxford: Routledge, 74-92.

Mıton, Kay, 1993: "Land or landscape: Rural Planning Policy and the Symbolic Construction of the Countryside" en Michael MurRay y John Greer (eds.): Rural Development in Ireland, Aldershot: Avebury, 120-150.

Nobs, Marie-Luise, 2006: La traducción de folletos turísticos ¿qué calidad demandan los turistas?, Granada: Comares.

Nord, Christiane, 1997: Translating as a Purposeful Activity: Functionalist Approaches Explained, Manchester: St. Jerome Publishing.

PIERINI, Patrizia, 2007: "Quality in Web Translation: An Investigation into UK and Italian Tourism Web Sites", The Journal of Specialized Translators 8, 85-103.

Pimentel, Luz Aurora, 2003: "Ecfrasis y lecturas iconotextuales", Poligrafías. Revista de Teoría Literaria y Literatura Comparada 4, 205-2015.

Pym, Anthony, 2008: "On Toury's Laws on How Translators Translate" en Anthony Prm, Miriam SHLESInger y Daniel SImeoni (eds.): Beyond Descriptive Translation, Studies: Investigations in homage to Gideon Toury, Ámsterdam, Filadelfia: John Benjamins, 311-328.

RAY, Rebecca, Nataly Kelly, 2010: Reaching New Markets Through Transcreation. When TransIation Just Isn't Enough, Lowell: Common Sense Advisory Inc.

ReIss, Katharina, 1976: Texttyp und Übersetzungsmethode: Der operative Text, Kronberg: Scriptor Verlag.

RiLey, Philip, 2002: "Epistemic Communities: The Social Knowledge System, Discourse and Identity” en Giuseppina Cortese y Philip Riley (eds.): Domain-specific English. Textual practices across communities and classrooms, Berna: Peter Lang, 41-64.

SULAIMAN, M. Zain, y Rita WILSON, 2018: "Translating tourism promotional materials: a culturalconceptual model", Perspectives. Studies in Translation Theory and Practice 26 (5), 629-645.

URRY, John, 1995: Consuming Places, Taylor \& Francis Group. 
URRY, John, 2005: "The Consuming of Place" en Adam Jaworski y Annette PrITCHARD (eds.): Discourse, Communication and Tourism, Clevedon/Buffalo/Toronto: Channel View Publications, 19-27.

Uzzell, David, 1984: "An alternative structuralist approach to the psychology of tourism marketing", Annals of Tourism Research 11, 79-99.

Valdés, Cristina, 2013: "Advertising Translation" en Carmen Millán y Frances BartRina (eds.): The Routledge handbook of translation studies, Londres: Routledge, 303-316.

Wagner, Peter (ed.), 1996: Icons - Texts - Iconotexts: Essays on Ekphrasis and Intermediality, Berlín, Nueva York: Walter de Gruyter.

Yuste FriAs, José (2015): "Paratraducción: la traducción de los márgenes, al margen de la traducción”, DELTA: Documentação de Estudos em Lingüística Teórica e Aplicada 31, 317-347 [https:// doi.org/10.1590/0102-445031725373379053].

ZukIN, Sharon, 1991: "Post-modern landscapes: mapping culture and power" en Scott LASH y Jonathan Friedman (eds.): Modernity and Identity, Oxford: Blackwell, 221-243. 